Review

\title{
Lung Transplantation for Pleuroparenchymal Fibroelastosis
}

\author{
Haruhiko Shiiya ${ }^{1,2} \mathbb{D}$ and Masaaki Sato ${ }^{1, *}$ \\ 1 Department of Thoracic Surgery, The University of Tokyo Graduate School of Medicine, 7-3-1 Hongo, \\ Bunkyo-ku, Tokyo 113-8655, Japan; shiiyah-sur@h.u-tokyo.ac.jp \\ 2 Department of Cardiovascular and Thoracic Surgery, Hokkaido University Graduate School of Medicine, \\ Kita 15 Nishi 7, Kita-ku, Sapporo 060-8638, Hokkaido, Japan \\ * Correspondence: satom-sur@h.u-tokyo.ac.jp; Tel.: +81-3-3815-5411; Fax: +81-3-5800-9156
}

\section{check for}

updates

Citation: Shiiya, H.; Sato, M. Lung Transplantation for

Pleuroparenchymal Fibroelastosis. J. Clin. Med. 2021, 10, 957. https:// doi.org/10.3390/jcm10050957

Academic Editor: Hiroshi Ishii

Received: 25 January 2021

Accepted: 20 February 2021

Published: 1 March 2021

Publisher's Note: MDPI stays neutral with regard to jurisdictional claims in published maps and institutional affiliations.

Copyright: (c) 2021 by the authors. Licensee MDPI, Basel, Switzerland. This article is an open access article distributed under the terms and conditions of the Creative Commons Attribution (CC BY) license (https:/ / creativecommons.org/licenses/by/ $4.0 /)$.

\begin{abstract}
Pleuroparenchymal fibroelastosis (PPFE), a new disease entity associated with interstitial pneumonia, is characterized by fibrosis and elastosis involving the pleura and subpleural lung parenchyma, predominantly in the upper lobe. As the awareness of this disease entity has increased, many studies have revealed the prevalence and incidence, clinical and pathological characteristics, and disease course of PPFE. Patients with PPFE reportedly have several unique clinical characteristics - including an extremely low body mass index with a slender body and chest wall deformity, known as "flat chest". As this disease progresses, shrinking of the lungs often causes life-threatening complications, such as pneumothorax, and associated air leak syndrome. Lung transplantation is considered the only effective treatment for patients with advanced PPFE; however, little is known about the influences of the characteristics of PPFE on the outcome of lung transplantation. This review focuses on the unique clinicopathologic characteristics of PPFE and associated outcomes of lung transplantation for these patients.
\end{abstract}

Keywords: lung transplantation; pleuroparenchymal fibroelastosis; interstitial lung disease; chest wall

\section{Introduction}

Pleuroparenchymal fibroelastosis (PPFE) is characterized by fibrosis involving the pleura and subpleural lung parenchyma, predominantly in the upper lobes. PPFE is broadly divided into two types: Idiopathic PPFE (IPPFE) and non-idiopathic PPFE. An associated condition termed idiopathic pulmonary upper lobe fibrosis was first reported by Amitani et al. [1] in 1992 in the Japanese literature. The term "idiopathic pleuroparenchymal fibroelastosis" was first used by Frankel et al. [2] in 2004, and IPPFE was formally included as a rare subtype in the international classification of the idiopathic interstitial pneumonias (IIPs) in 2013 [3]. Since then, the awareness of this disease entity has increased, and several characteristic clinical features have been reported; patients with IPPFE often have a slender body and a low body mass index (BMI) [4], and many develop a chest wall deformity known as "flat chest" [5]. In the advanced stage of the disease, shrinking of the lungs often causes pneumothorax and associated air leak syndrome (ALS) [6-9]. No medical treatment has been shown to be effective, and lung transplantation (LT) is, therefore, considered a therapeutic option for patients with advanced PPFE. Although few data regarding the outcomes of LT for patients with PPFE are available, complicated post-LT courses associated with the unique features of PPFE have been reported. This narrative review focuses on the difficulties, challenges, and future perspectives of LT for patients with PPFE.

\section{Prevalence and Incidence of PPFE}

The number of reports associated with PPFE has increased during the last decade. However, no international consensus regarding the diagnostic criteria has been established, and the accurate prevalence and incidence of PPFE, therefore, remain unknown. Before IPPFE was included in the new classification of IIPs in 2013, PPFE may have been diagnosed as other IIPs, mostly idiopathic pulmonary fibrosis (IPF). Most previous reports 
describing the prevalence and incidence of IPPFE were reviews of patients with IIPs. The reported prevalence of a PPFE pattern in patients with IIPs is around 5.8-10.4\% [10-13]. Oda et al. [10] reported that $11(10 \%)$ of 110 patients with IPF had radiological PPFE and that $9(8.2 \%)$ of these patients' conditions fulfilled the histologic criteria for PPFE. Nakatani et al. [11] retrospectively reviewed 205 patients who underwent surgical lung biopsy for interstitial lung diseases (ILDs) and found that $12(5.8 \%)$ had PPFE. They also reported that the frequency of IPPFE among IIPs was 10.4\% [11]. Shioya et al. [12] reviewed 375 patients with IIPs and found that $29(7.7 \%)$ met radiological criteria for IPPFE. Lee et al. [13] reviewed 445 patients with IPF and identified PPFE in 28 (6.3\%). The frequency of PPFE among patients with ILDs is reportedly higher when the analysis is limited to LT candidates. A Japanese single-institution study showed that among 118 patients with ILDs listed for LT, 30 (25\%) were diagnosed with radiological PPFE [14]. We previously reported that $8(28 \%)$ of 29 LT candidates with IIPs were diagnosed with IPPFE [15]. Many previous reports describing the prevalence of IPPFE were from Japanese authors. Whether the prevalence and incidence of IPPFE in the Japanese population are higher than those in Western populations should be investigated further.

Non-idiopathic PPFE reportedly occurs mainly after chemotherapy, allogeneic hematopoietic stem cell transplantation (HSCT), allogeneic bone marrow transplantation (BMT), and LT. Mariani et al. [16] reviewed high-resolution computed tomography examination findings from $700 \mathrm{HSCT}$ recipients and $53 \mathrm{LT}$ recipients. Among them, the imaging findings of two $(0.28 \%)$ HSCT recipients and four (7.5\%) LT recipients were identified as clinically and radiologically consistent with PPFE [16]. PPFE associated with connective tissue disease has also been reported. Enomoto et al. [17] reviewed 113 patients with connective tissue disease-related ILDs and found radiologic PPFE-like lesions in 21 (19\%) patients. Recently, Bonifazi et al. [18] identified PPFE in 65 (18.1\%) of 359 patients with systemic sclerosis. Most patients with restrictive allograft syndrome, one of the clinical subtypes of chronic lung allograft dysfunction (CLAD), reportedly show a histological PPFE pattern [19]. CLAD is reported to occur in approximately $50 \%$ of recipients by five years after LT [20], and restrictive allograft syndrome is reported to account for $25 \%$ to $35 \%$ of cases of CLAD [21].

\section{Clinical Characteristics of PPFE}

Many papers have described the characteristic clinical and laboratory findings of PPFE, and excellent review articles have been published $[4,22,23]$. In the present review, therefore, we focus on the characteristic features and complications that may affect the outcomes after LT.

\section{1. $B M I$}

In general, an underweight status before LT is reportedly associated with worse survival after LT, although the optimal cutoff value of the BMI varies among different reports. Upala et al. [24] reported a significant risk of mortality after LT in candidates with a BMI of $<18.5 \mathrm{~kg} / \mathrm{m}^{2}$ [relative risk, 1.36; 95\% confidence interval (CI), 1.11-1.66]. Singer et al. [25] reported that a BMI of $<18.5 \mathrm{~kg} / \mathrm{m}^{2}$ was associated with a $35 \%$ increased mortality ( $95 \%$ CI, $10-66 \%$ ). Fernandez et al. [26] reported that a BMI of $<20 \mathrm{~kg} / \mathrm{m}^{2}$ in a cohort of patients with restrictive lung disease was associated with an increased risk of mortality at one year after LT (odds ratio, 1.23; 95\% CI, 1.02-1.48). Komatsu et al. [27] proposed an optimal BMI cutoff of $<17.0 \mathrm{~kg} / \mathrm{m}^{2}$ as indicative of a pre-LT underweight status.

Patients with IPPFE have been reported to have a lower BMI than patients with IPF $[10,12,13,28]$. Oda et al. [10] evaluated nine patients with PPFE and a usual interstitial pneumonia (UIP) pattern, and their BMI (mean \pm standard deviation) was $18.6 \pm 1.8 \mathrm{~kg} / \mathrm{m}^{2}$. Shioya et al. [12] reported that the mean BMI of 29 patients with radiological IPPFE was $20.1 \pm 3.25 \mathrm{~kg} / \mathrm{m}^{2}$. Lee et al. [13] reported that the coexistence of radiological PPFE in patients with IPF was associated with a lower BMI (PPFE, $21.2 \pm 3.0 \mathrm{~kg} / \mathrm{m}^{2} \mathrm{vs}$. non-PPFE, $24.4 \pm 3.1 \mathrm{~kg} / \mathrm{m}^{2}$ ). Enomoto et al. [28] reported that 44 patients with radio- 
logical IPPFE had a median BMI of $17.2 \mathrm{~kg} / \mathrm{m}^{2}$ [interquartile range (IQR), 14.7-18.5]. We previously reported that the median pre-LT BMI of Japanese recipients with IPPFE was $16.7 \mathrm{~kg} / \mathrm{m}^{2}$ [29]. Among patients with connective tissue disease, a radiological PPFE-like region is reportedly associated with a low BMI (median, $19.8 \mathrm{~kg} / \mathrm{m}^{2}$; IQR, 17.3-22.4) [17]. Tanizawa et al. [14] reviewed LT candidates with ILDs and reported that the median BMI of 30 patients with radiological PPFE was $15.9 \mathrm{~kg} / \mathrm{m}^{2}$ (IQR, 14.8-17.2). Thus, a substantial proportion of patients with PPFE have an extremely low BMI, which might predict worse survival after LT.

No data regarding the association between the low BMI in patients with PPFE and post-LT outcomes are currently available. In general, severe malnutrition is considered to be a relative contraindication for LT [30]. Given that a substantial proportion of patients with PPFE has a low BMI, the post-LT outcomes in patients with PPFE might be poor; however, the low BMI may not necessarily represent malnutrition and lead to poor outcomes. Indeed, in our previous work, the overall survival after LT in patients with IPPFE was similar to that in patients with IPF [29]. In patients with cystic fibrosis, weight loss often occurs secondary to maldigestion, malabsorption, and associated malnutrition. Malnutrition in patients with cystic fibrosis is reportedly associated with worse survival and pulmonary function after LT [31,32]. Whether the low BMI in patients with PPFE results from malnutrition and affects post-LT outcomes should be investigated in further studies. Other parameters that reflect frailty or the nutritional status, such as the muscle mass [33], bioelectrical impedance analysis results [34], and nutritional risk index [35], should also be evaluated in future studies. Moreover, severe restrictive dysfunction in patients with PPFE might result in increased respiratory effort and energy consumption.

\subsection{Flat Chest}

Patients with PPFE often develop a flattening of the thoracic cage with the progression of the disease [5] (Figure 1). Chest deformity may result in the restriction of lung expansion after LT, and severe chest wall deformity is often considered an absolute contraindication for LT [30]; however, studies have shown that flat chest is not always associated with a poor outcome after LT. Miyoshi et al. [36] reported that pulmonary function after livingdonor LT in patients with flat chest was poorer than that in patients with a normal chest, whereas the post-LT exercise capacity was equivalent, and the flat chest severity improved after LT. Miyahara et al. [37] reported that pulmonary function, exercise capacity, and survival in patients with flat chest after deceased-donor LT were similar to those in patients with a normal chest. Poorer pulmonary function after living-donor LT might be partly attributed to a lower volume of the donor lungs; living-donor LT usually uses two lung lobes, which have a smaller volume than the whole lungs used in deceased-donor LT. These two reports $[36,37]$ were not limited to patients with PPFE; they included patients with other lung diseases and pulmonary hypertension. Patients with advanced ILDs and some congenital conditions, such as pectus excavatum, may show a flattening of the chest wall. Flat chest in patients with PPFE may be slightly different from that in patients with other diseases. In our previous report, pulmonary functions in patients with IPPFE after both deceased-donor and living-donor LT were poorer than those in patients with IPF [29]. These differences between patients with IPPFE and those with other diseases suggest that not only the lung volume itself, but other problems, such as a rigid chest wall, might persist and limit the function of patients with IPPFE even after LT. Yanagiya et al. [38] described a patient who required intensive pulmonary rehabilitation because of chest wall rigidity despite the fact that the chest wall flatness was reversed after LT. The mechanism underlying the development of flat chest in patients with PPFE should be investigated further. 


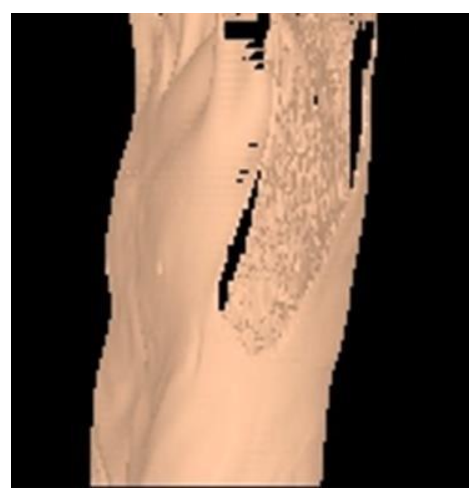

(a)

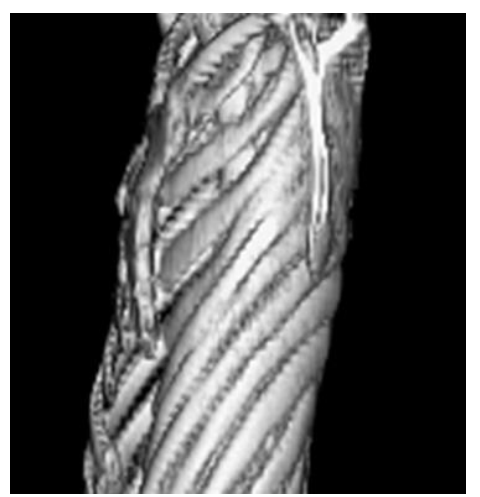

(b)

Figure 1. 3D-CT of a patient with pleuroparenchymal fibroelastosis. (a) 3D-CT with body surface. Flattening of the chest wall is shown. (b) 3D-CT with bone reconstruction. The intercostal spaces are narrow, and the anteroposterior diameter is shortened. Abbreviation: 3D-CT-three-dimensional computed tomography.

\subsection{Pneumothorax and ALS}

Pneumothorax is one of the major complications in patients with both IPPFE and non-idiopathic PPFE. The incidence of pneumothorax in patients with PPFE is apparently higher than that in other IIPs. Enomoto et al. [28] reported that 8 (18\%) of 44 patients with PPFE had a history of pneumothorax at the time of diagnosis. Lee et al. [13] reported that 5 $(17.9 \%)$ of 28 patients who had IPF with radiological PPFE developed pneumothorax during the median follow-up period of 43.0 months. The incidence of pneumothorax is reportedly higher in LT candidates, who usually have advanced disease. Tanizawa et al. [14] reported that $24(80 \%)$ of 30 patients with radiological PPFE had a history of pneumothorax at the time of registration for LT. We previously reported 31 recipients with IPPFE who underwent LT; among them, 16 (52\%) had a history of pneumothorax at the time of LT [29].

Post-transplant ALS, including pneumothorax, subcutaneous emphysema, and pneumomediastinum, is known to occur after allogeneic HSCT or BMT [6-9]. PPFE-related ALS was recently recognized as a lung complication after allogeneic HSCT and allogeneic BMT $[9,39]$. Patients with IPPFE can also develop ALS at an advanced stage of the disease (Figure 2). ALS is sometimes life-threatening [6,7], can be recurrent [40], and often leads to fungal infection $[6,41]$, which may result in mortality before LT.

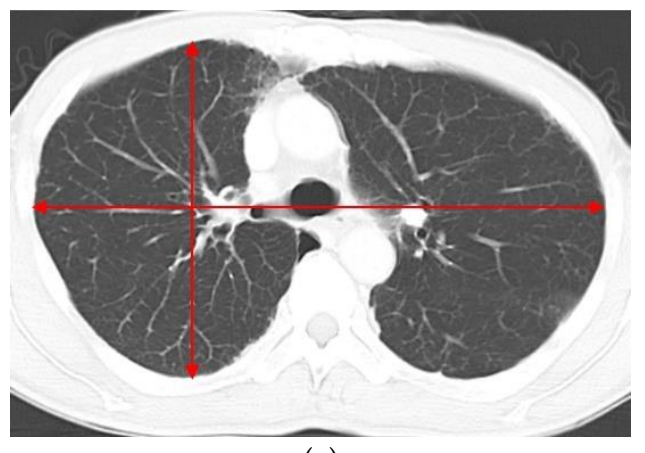

(a)

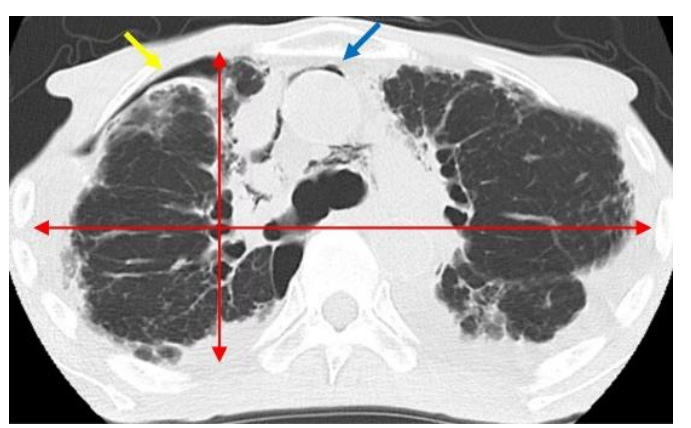

(b)

Figure 2. Chest CT images of a patient with idiopathic pleuroparenchymal fibroelastosis (IPPFE). (a) Chest CT before the diagnosis of IPPFE at the level of the sixth thoracic vertebra. The bilateral lungs are almost normal. (b) Chest CT 7 years later at the same level. The anteroposterior diameter of the thoracic cage has become shortened. Shrinking of the lungs has resulted in an air space in the right chest cavity (yellow arrow) and pneumomediastinum (blue arrow), indicating air leak syndrome. Abbreviations: CT—computed tomography; IPPFE—idiopathic pleuroparenchymal fibroelastosis. 
Recurrent or prolonged pneumothorax and ALS sometimes necessitate interventions, such as pleurodesis and surgical repair, including pleural covering [9,42]. Severe adhesion in the chest cavity may lead to prolonged surgical and ischemic times and a higher rate of bleeding, resulting in delayed recovery and poorer outcomes after LT. These conditions may be exacerbated by longer cardiopulmonary bypass times. Drainage or observation may be preferred to pleurodesis in sufficient cases; however, pneumothorax in a future recipient for LT should be given the best immediate management to avoid missing the opportunity to undergo LT [30]. Pleurodesis and previous surgery are usually not contraindications for LT. Recurrent pneumothorax and ALS may cause adhesion even if pleurodesis is avoided.

\section{Optimal Timing of LT}

The natural course and prognosis of PPFE are highly variable. An analysis of 85 patients, including patients with both IPPFE and secondary PPFE, demonstrated a relatively long median survival of 11 years [22]. A subsequent study, however, revealed the presence of a rapidly progressing phenotype of IPPFE [43], and several studies have shown worse survival of patients with IPPFE than IPF $[12,44]$. The differences among these studies may be partly due to the timing of the diagnosis; most patients with IPPFE are diagnosed at the advanced stage. Patients with IPPFE may have a long subclinical stage with only small changes in the upper lobes [22]. Another important matter is the heterogeneity of PPFE. The coexistence of the PPFE pattern and other ILDs is apparently not uncommon [17,45]. Several studies have shown that the coexistence of a UIP pattern predicts a poorer prognosis in patients with IPPFE [13,46,47], although one study failed to show a significant impact of the presence of a UIP pattern on the prognosis of patients with IPPFE [28]. The coexistence of a PPFE pattern in patients with chronic hypersensitivity pneumonitis has also been reported to be associated with increased mortality [48]. In contrast, one study showed that after adjustment for age, sex, percent predicted forced vital capacity (FVC), and 6-min walk distance, patients with IPPFE and late-onset noninfectious pulmonary complications after HSCT and/or chemotherapy with a radiological PPFE pattern had better survival than patients with fibrotic ILDs without a radiological PPFE pattern [14]. Patients with IPPFE often show a disproportionate reduction in the FVC with a relatively preserved diffusing capacity [22]; therefore, the FVC may not always precisely represent the general condition in patients with IPPFE. Our previous small study of LT candidates suggested long-term survival despite unfavorable prognostic factors, including a low BMI and a short 6-min walk distance [15].

The optimal timing to list patients with PPFE on the waiting list for LT is still unknown. The proposal by the international guideline for the timing of listing patients with ILD for LT is based on a decline in the FVC, diffusing capacity, desaturation, and exercise capacity. The presence of pulmonary hypertension, pneumothorax, and acute exacerbation are also factors associated with the timing of listing [30]. Based on the current knowledge, the disease course of patients with PPFE is not always the same as that of patients with other ILDs, and some patients with PPFE may survive longer than patients with other ILDs; however, the survival of most patients with PPFE after diagnosis is as poor as that of patients with other ILDs.

\section{Post-LT Course}

Few data are available regarding the outcomes of LT for PPFE. Several authors have reported good post-LT courses without complications (Table 1). Chen et al. [49] described a patient with PPFE after chemotherapy for leukemia who was treated with single LT. The postoperative course was uneventful, and the patient was doing well four months after LT. Hata et al. [50] also reported an uneventful clinical course after living-donor lobar LT (LDLLT) for PPFE associated with chemotherapy. Rasciti et al. [51] described a patient with IPPFE who underwent bilateral LT. Although relapse of PPFE was suspected as a late complication, the postoperative course was uneventful. In contrast, several case reports have described complicated postoperative courses. Shimada et al. [52] reported PPFE 
associated with allogeneic umbilical cord stem cell transplantation. The patient underwent extracorporeal membrane oxygenation-bridged LDLLT and spent 30 days in the intensive care unit, but thereafter recovered and did well for one year. Yanagiya et al. [38] described a patient with IPPFE and flat chest who underwent LDLLT. The authors reported the necessity of intensive pulmonary rehabilitation for chest wall rigidity [38]. Righi et al. [53] also described a patient with IPPFE who required long-term rehabilitation after LT. We previously reported a case of fatal secondary pulmonary hypertension associated with flat chest in a patient with IPPFE who underwent single LT [54]. Other authors have also reported complicated post-LT courses [55-57]; however, after recovery from early complications, such as chylothorax, dysphagia, vocal cord paralysis, pneumonia, and repeated nausea and vomiting for an unknown reason, the patients apparently did well. There are also several case reports of LT for IPPFE or non-idiopathic PPFE without detailed information about the post-LT course [58-60]. To the best of our knowledge, our previous study of 31 patients with IPPFE in Japan is the largest study to show the outcomes after LT. In that study, although patients with IPPFE had a longer stay in the intensive care unit and the hospital, and although the low BMI and the low FVC persisted even after LT, the overall survival was similar to that of patients with IPF [29]. Based on the current knowledge, LT can be performed successfully and achieve acceptable survival for patients with PPFE; however, the post-LT course can be complicated, and some functional problems may persist even after LT. Further studies are necessary to obtain accurate knowledge regarding the outcome of LT for PPFE. The incidence of CLAD and other late complications should also be determined in further studies.

Table 1. Published case reports describing lung transplantation for PPFE.

\begin{tabular}{|c|c|c|c|c|c|c|}
\hline Author & Sex & Age & Underlying Condition & Procedure & $\begin{array}{l}\text { Posttransplant } \\
\text { Course }\end{array}$ & Outcome \\
\hline Chen et al. (2014) & Male & 14 & Chemotherapy & Left single & uneventful & Alive \\
\hline Portillo et al. (2015) & Male & 25 & Castleman's disease & Bilateral & NA & Alive \\
\hline Hata et al. (2016) & Male & 19 & Chemotherapy & LDLLT & uneventful & Alive \\
\hline $\begin{array}{c}\text { Yanagiya et al. } \\
\text { (2016) }\end{array}$ & Female & 27 & Idiopathic & LDLLT & complicated & Alive \\
\hline Huan et al. (2017) & Male & 34 & Idiopathic & Bilateral & NA & NA \\
\hline $\begin{array}{c}\text { Shimada et al. } \\
\text { (2018) }\end{array}$ & Female & 21 & HSCT & LDLLT & complicated & Alive \\
\hline $\begin{array}{c}\text { Tsubosaka et al. } \\
\text { (2018) }\end{array}$ & Male & 19 & Chemotherapy & Living-donor & NA & NA \\
\hline Righi et al. (2018) & Male & 42 & Idiopathic & Bilateral & complicated & Alive \\
\hline Ali et al. (2019) & Female & 26 & Idiopathic & Bilateral & complicated & Alive \\
\hline Aljefri et al. (2019) & Male & 27 & Idiopathic & Bilateral & complicated & Alive \\
\hline Sekine et al. (2020) & Female & 29 & Idiopathic & LDLLT & complicated & Alive \\
\hline Rasciti et al. (2020) & Male & 48 & Idiopathic & Bilateral & possible PPFE relapse & Re-transplant \\
\hline Shiiya et al. (2020) & Female & 40 & Idiopathic & Left single & complicated & Dead \\
\hline
\end{tabular}

Abbreviations: HSCT—hematopoietic stem cell transplantation; LDLLT—living-donor lobar lung transplantation; NA—not available; PPFE-pleuroparenchymal fibroelastosis.

\section{Conclusions}

Few data are available regarding the optimal strategy to achieve the best outcome after LT for patients with PPFE. Further studies are needed to obtain accurate knowledge regarding LT for PPFE. Based on the current knowledge, unique characteristics of patients with PPFE may result in a complicated intraoperative and short-term post-LT course; however, the long-term outcomes are apparently similar to those of patients with other ILDs. As the only therapeutic option for patients with PPFE, LT should be considered in the advanced stage of the disease. Clinicians should consider the distinct characteristics of patients with PPFE when considering the possibility of LT, follow up patients on the waiting list, and follow up patients after LT. Further studies should also address the underlying mechanism of PPFE. 
Author Contributions: Conceptualization, M.S. and H.S.; methodology, H.S. and M.S.; validation, H.S. and M.S.; investigation, H.S.; data curation, H.S. and M.S.; writing - original draft preparation, H.S.; writing-review and editing, H.S. and M.S.; visualization, H.S.; supervision, M.S.; project administration, M.S. All authors have read and agreed to the published version of the manuscript.

Funding: This research received no external funding.

Data Availability Statement: This study did not report any data.

Acknowledgments: We thank Angela Morben, DVM, ELS, from Edanz Group (https: / / en-authorservices.edanz.com/ac accessed on 25 January 2021), for editing a draft of this manuscript.

Conflicts of Interest: The authors declare no conflict of interest.

\section{References}

1. Amitani, R.; Niimi, A.; Kuse, F. Idiopathic pulmonary upper lobe fibrosis. Kokyu 1992, 11, 693-699.

2. Frankel, S.K.; Cool, C.D.; Lynch, D.A.; Brown, K.K. Idiopathic pleuroparenchymal fibroelastosis: Description of a novel clinicopathologic entity. Chest 2004, 126, 2007-2013. [CrossRef] [PubMed]

3. Travis, W.D.; Costabel, U.; Hansell, D.M.; King, T.E.; Lynch, D.A.; Nicholson, A.G.; Ryerson, C.J.; Ryu, J.H.; Selman, M.; Wells, A.U.; et al. An official American Thoracic Society/European Respiratory Society statement: Update of the international multidisciplinary classification of the idiopathic interstitial pneumonias. Am. J. Respir. Crit. Care Med. 2013, 188, 733-748. [CrossRef]

4. Bonifazi, M.; Montero, M.A.; Renzoni, E.A. Idiopathic Pleuroparenchymal Fibroelastosis. Curr. Pulmonol. Rep. 2017, 6, 9-15. [CrossRef]

5. Harada, T.; Yoshida, Y.; Kitasato, Y.; Tsuruta, N.; Wakamatsu, K.; Hirota, T.; Tanaka, M.; Tashiro, N.; Ishii, H.; Shiraishi, M.; et al. The thoracic cage becomes flattened in the progression of pleuroparenchymal fibroelastosis. Eur. Respir. Rev. 2014, 23, 263-266. [CrossRef] [PubMed]

6. Vogel, M.; Brodoefel, H.; Bethge, W.; Faul, C.; Hartmann, J.; Schimmel, H.; Wehrmann, M.; Claussen, C.D.; Horger, M. Spontaneous thoracic air-leakage syndrome in patients following allogeneic hematopoietic stem cell transplantation: Causes, CT-follow up and patient outcome. Eur. J. Radiol. 2006, 60, 392-397. [CrossRef]

7. Franquet, T.; Rodríguez, S.; Hernández, J.M.; Martino, R.; Giménez, A.; Hidalgo, A.; Domingo, P. Air-leak syndromes in hematopoietic stem cell transplant recipients with chronic GVHD: High-resolution CT findings. J. Thorac. Imaging 2007, 22, 335-340. [CrossRef] [PubMed]

8. Sakai, R.; Kanamori, H.; Nakaseko, C.; Yoshiba, F.; Fujimaki, K.; Sakura, T.; Fujisawa, S.; Kawai, N.; Onoda, M.; Matsushima, T.; et al. Air-leak syndrome following allo-SCT in adult patients: Report from the Kanto Study Group for Cell Therapy in Japan. Bone Marrow Transpl. 2011, 46, 379-384. [CrossRef]

9. Ishii, T.; Bando, S.; Kanaji, N.; Tadokoro, A.; Watanabe, N.; Imataki, O.; Dobashi, H.; Kushida, Y.; Haba, R.; Yokomise, H. Air-leak syndrome by pleuroparenchymal fibroelastosis after bone marrow transplantation. Intern. Med. 2016, 55, 105-111. [CrossRef]

10. Oda, T.; Ogura, T.; Kitamura, H.; Hagiwara, E.; Baba, T.; Enomoto, Y.; Iwasawa, T.; Okudela, K.; Takemura, T.; Sakai, F.; et al. Distinct characteristics of pleuroparenchymal fibroelastosis with usual interstitial pneumonia compared with idiopathic pulmonary fibrosis. Chest 2014, 146, 1248-1255. [CrossRef]

11. Nakatani, T.; Arai, T.; Kitaichi, M.; Akira, M.; Tachibana, K.; Sugimoto, C.; Hirooka, A.; Tsuji, T.; Minomo, S.; Hayashi, S.; et al. Pleuroparenchymal fibroelastosis from a consecutive database: A rare disease entity? Eur. Respir. J. 2015, 45, 1183-1186. [CrossRef] [PubMed]

12. Shioya, M.; Otsuka, M.; Yamada, G.; Umeda, Y.; Ikeda, K.; Nishikiori, H.; Kuronuma, K.; Chiba, H.; Takahashi, H. Poorer Prognosis of Idiopathic Pleuroparenchymal Fibroelastosis Compared with Idiopathic Pulmonary Fibrosis in Advanced Stage. Can. Respir. J. 2018, 2018, 6043053. [CrossRef] [PubMed]

13. Lee, S.I.; Chae, E.J.; Song, J.S.; Lee, J.H.; Song, J.W. Pleuroparenchymal fibroelastosis in patients with idiopathic pulmonary fibrosis. Respirology 2020, 25, 1046-1052. [CrossRef]

14. Tanizawa, K.; Handa, T.; Kubo, T.; Chen-Yoshikawa, T.F.; Aoyama, A.; Motoyama, H.; Hijiya, K.; Yoshizawa, A.; Oshima, Y.; Ikezoe, K.; et al. Clinical significance of radiological pleuroparenchymal fibroelastosis pattern in interstitial lung disease patients registered for lung transplantation: A retrospective cohort study. Respir. Res. 2018, 19, 162. [CrossRef] [PubMed]

15. Shiiya, H.; Tian, D.; Sato, M.; Karasaki, T.; Kitano, K.; Nagayama, K.; Anraku, M.; Kaga, K.; Matsui, Y.; Nakajima, J. Differences Between Patients with Idiopathic Pleuroparenchymal Fibroelastosis and Those with Other Types of Idiopathic Interstitial Pneumonia in Candidates for Lung Transplants. Transplant. Proc. 2019, 51, 2014-2021. [CrossRef] [PubMed]

16. Mariani, F.; Gatti, B.; Rocca, A.; Bonifazi, F.; Cavazza, A.; Fanti, S.; Tomassetti, S.; Piciucchi, S.; Poletti, V.; Zompatori, M. Pleuroparenchymal fibroelastosis: The prevalence of secondary forms in hematopoietic stem cell and lung transplantation recipients. Diagn. Interv. Radiol. 2016, 22, 400-406. [CrossRef]

17. Enomoto, Y.; Nakamura, Y.; Colby, T.V.; Johkoh, T.; Sumikawa, H.; Nishimoto, K.; Yoshimura, K.; Matsushima, S.; Oyama, Y.; Hozumi, H.; et al. Radiologic pleuroparenchymal fibroelastosis-like lesion in connective tissue disease-related interstitial lung disease. PLoS ONE 2017, 12, e0180283. [CrossRef] 
18. Bonifazi, M.; Sverzellati, N.; Negri, E.; Jacob, J.; Egashira, R.; Moser, J.; Piciucchi, S.; Mei, F.; De Lauretis, A.; Visca, D.; et al. Pleuroparenchymal fibroelastosis in systemic sclerosis: Prevalence and prognostic impact. Eur. Respir. J. 2020, $56,1902135$. [CrossRef]

19. Ofek, E.; Sato, M.; Saito, T.; Wagnetz, U.; Roberts, H.C.; Chaparro, C.; Waddell, T.K.; Singer, L.G.; Hutcheon, M.A.; Keshavjee, S.; et al. Restrictive allograft syndrome post lung transplantation is characterized by pleuroparenchymal fibroelastosis Mod. Pathol. 2013, 26, 350-356. [CrossRef]

20. Royer, P.J.; Olivera-Botello, G.; Koutsokera, A.; Aubert, J.D.; Bernasconi, E.; Tissot, A.; Pison, C.; Nicod, L.; Boissel, J.P.; Magnan, A. Chronic lung allograft dysfunction: A systematic review of mechanisms. Transplantation 2016, 100, 1803-1814. [CrossRef] [PubMed]

21. Sato, M.; Waddell, T.K.; Wagnetz, U.; Roberts, H.C.; Hwang, D.M.; Haroon, A.; Wagnetz, D.; Chaparro, C.; Singer, L.G.; Hutcheon, M.A.; et al. Restrictive allograft syndrome (RAS): A novel form of chronic lung allograft dysfunction. J. Heart Lung Transplant. 2011, 30, 735-742. [CrossRef]

22. Watanabe, K. Pleuroparenchymal Fibroelastosis: Its Clinical Characteristics. Curr. Respir. Med. Rev. 2013, 9, 229-237. [CrossRef]

23. Chua, F.; Desai, S.R.; Nicholson, A.G.; Devaraj, A.; Renzoni, E.; Rice, A.; Wells, A.U. Pleuroparenchymal fibroelastosis a review of clinical, radiological, and pathological characteristics. Ann. Am. Thorac. Soc. 2019, 16, 1351-1359. [CrossRef]

24. Upala, S.; Panichsillapakit, T.; Wijarnpreecha, K.; Jaruvongvanich, V.; Sanguankeo, A. Underweight and obesity increase the risk of mortality after lung transplantation: A systematic review and meta-analysis. Transpl. Int. 2016, 29, 285-296. [CrossRef] [PubMed]

25. Singer, J.P.; Peterson, E.R.; Snyder, M.E.; Katz, P.P.; Golden, J.A.; D’Ovidio, F.; Bacchetta, M.; Sonett, J.R.; Kukreja, J.; Shah, L.; et al. Body composition and mortality after adult lung transplantation in the United States. Am. J. Respir. Crit. Care Med. 2014, 190, 1012-1021. [CrossRef] [PubMed]

26. Fernandez, R.; Safaeinili, N.; Kurihara, C.; Odell, D.D.; Jain, M.; DeCamp, M.M.; Budinger, G.R.S.; Bharat, A. Association of body mass index with lung transplantation survival in the United States following implementation of the lung allocation score. J. Thorac. Cardiovasc. Surg. 2018, 155, 1871-1879.e3. [CrossRef]

27. Komatsu, T.; Chen-Yoshikawa, T.F.; Oshima, A.; Harashima, S.-I.; Aoyama, A.; Inagaki, N.; Date, H. Severe underweight decreases the survival rate in adult lung transplantation. Surg. Today 2017, 47, 1243-1248. [CrossRef]

28. Enomoto, Y.; Nakamura, Y.; Satake, Y.; Sumikawa, H.; Johkoh, T.; Colby, T.V.; Yasui, H.; Hozumi, H.; Karayama, M.; Suzuki, Y.; et al. Clinical diagnosis of idiopathic pleuroparenchymal fibroelastosis: A retrospective multicenter study. Respir. Med. 2017, 133, 1-5. [CrossRef]

29. Shiiya, H.; Nakajima, J.; Date, H.; Chen-Yoshikawa, T.F.; Tanizawa, K.; Handa, T.; Oto, T.; Otani, S.; Shiotani, T.; Okada, Y.; et al. Outcomes of lung transplantation for idiopathic pleuroparenchymal fibroelastosis. Surg. Today 2021. [CrossRef] [PubMed]

30. Weill, D.; Benden, C.; Corris, P.A.; Dark, J.H.; Davis, R.D.; Keshavjee, S.; Lederer, D.J.; Mulligan, M.J.; Patterson, G.A.; Singer, L.G.; et al. A consensus document for the selection of lung transplant candidates: 2014-An update from the Pulmonary Transplantation Council of the International Society for Heart and Lung Transplantation. J. Heart Lung Transplant. 2015, 34, 1-15. [CrossRef]

31. Staufer, K.; Halilbasic, E.; Hillebrand, P.; Harm, S.; Schwarz, S.; Jaksch, P.; Kivaranovic, D.; Klepetko, W.; Trauner, M.; KazemiShirazi, L. Impact of nutritional status on pulmonary function after lung transplantation for cystic fibrosis. United Eur. Gastroenterol. J. 2018, 6, 1049-1055. [CrossRef] [PubMed]

32. Hollander, F.M.; van Pierre, D.D.; de Roos, N.M.; van de Graaf, E.A.; Iestra, J.A. Effects of nutritional status and dietetic interventions on survival in Cystic Fibrosis patients before and after lung transplantation. J. Cyst. Fibros. 2014, 13, 212-218. [CrossRef]

33. Kashani, K.; Sarvottam, K.; Pereira, N.L.; Barreto, E.F.; Kennedy, C.C. The sarcopenia index: A novel measure of muscle mass in lung transplant candidates. Clin. Transplant. 2018, 32, e13182. [CrossRef]

34. Suzuki, Y.; Yoshimura, K.; Enomoto, Y.; Yasui, H.; Hozumi, H.; Karayama, M.; Furuhashi, K.; Enomoto, N.; Fujisawa, T.; Nakamura, Y.; et al. Distinct profile and prognostic impact of body composition changes in idiopathic pulmonary fibrosis and idiopathic pleuroparenchymal fibroelastosis. Sci. Rep. 2018, 8, 14074. [CrossRef] [PubMed]

35. Chohan, K.; Park, J.; Dales, S.; Varughese, R.; Wickerson, L.; Singer, L.G.; Stewart, B.; Rozenberg, D. Evaluation of Malnutrition Risk in Lung Transplant Candidates Using the Nutritional Risk Index. Transplant. Direct 2020, 6, e574. [CrossRef]

36. Miyoshi, R.; Chen-Yoshikawa, T.F.; Takahagi, A.; Oshima, Y.; Hijiya, K.; Motoyama, H.; Aoyama, A.; Date, H. Pulmonary Function and Exercise Capacity in Patients with Flat Chests After Lung Transplantation. Ann. Thorac. Surg. 2017, 104, 1695-1701. [CrossRef]

37. Miyahara, S.; Chen-Yoshikawa, T.F.; Motoyama, H.; Nakajima, D.; Hamaji, M.; Aoyama, A.; Date, H. Impact of flat chest on cadaveric lung transplantation: Postoperative pulmonary function and survival. Eur. J. Cardio Thorac. Surg. 2019, 55, 316-322. [CrossRef]

38. Yanagiya, M.; Sato, M.; Kawashima, S.; Kuwano, H.; Nagayama, K.; Nitadori, J.-I.; Anraku, M.; Nakajima, J. Flat Chest of Pleuroparenchymal Fibroelastosis Reversed by Lung Transplantation. Ann. Thorac. Surg. 2016, 102, e347-e349. [CrossRef]

39. Von Der Thüsen, J.H.; Hansell, D.M.; Tominaga, M.; Veys, P.A.; Ashworth, M.T.; Owens, C.M.; Nicholson, A.G. Pleuroparenchymal fibroelastosis in patients with pulmonary disease secondary to bone marrow transplantation. Mod. Pathol. 2011, 24, 1633-1639. [CrossRef] [PubMed] 
40. Matsui, T.; Maeda, T.; Kida, T.; Fujita, J.; Tsuji, H.; Morii, E.; Kanakura, Y. Pleuroparenchymal fibroelastosis after allogenic hematopoietic stem cell transplantation: Important histological component of late-onset noninfectious pulmonary complication accompanied with recurrent pneumothorax. Int. J. Hematol. 2016, 104, 525-530. [CrossRef]

41. Liu, Y.C.; Chou, Y.H.; Ko, P.S.; Wang, H.Y.; Fan, N.W.; Liu, C.J.; Hsiao, L.T.; Chien, S.H.; Chiou, T.J.; Liu, J.H.; et al. Risk factors and clinical features for post-transplant thoracic air-leak syndrome in adult patients receiving allogeneic haematopoietic stem cell transplantation. Sci. Rep. 2019, 9, 11795. [CrossRef]

42. Kunou, H.; Kanzaki, R.; Kawamura, T.; Kanou, T.; Ose, N.; Funaki, S.; Shintani, Y.; Minami, M.; Okumura, M. Two cases of air leak syndrome after bone marrow transplantation successfully treated by the pleural covering technique. Gen. Thorac. Cardiovasc. Surg. 2019, 67, 987-990. [CrossRef]

43. Yoshida, Y.; Nagata, N.; Tsuruta, N.; Kitasato, Y.; Wakamatsu, K.; Yoshimi, M.; Ishii, H.; Hirota, T.; Hamada, N.; Fujita, M.; et al. Heterogeneous clinical features in patients with pulmonary fibrosis showing histology of pleuroparenchymal fibroelastosis. Respir. Investig. 2016, 54, 162-169. [CrossRef]

44. Suzuki, Y.; Fujisawa, T.; Sumikawa, H.; Tanaka, T.; Sugimoto, C.; Kono, M.; Hozumi, H.; Karayama, M.; Furuhashi, K.; Enomoto, N.; et al. Disease course and prognosis of pleuroparenchymal fibroelastosis compared with idiopathic pulmonary fibrosis. Respir. Med. 2020, 171, 106078. [CrossRef] [PubMed]

45. Sumikawa, H.; Johkoh, T.; Egashira, R.; Sugiura, H.; Yamano, Y.; Kataoka, K.; Kondoh, Y.; Arakawa, H.; Nakamura, M.; Kuriu, A.; et al. Pleuroparenchymal fibroelastosis-like lesions in patients with interstitial pneumonia diagnosed by multidisciplinary discussion with surgical lung biopsy. Eur. J. Radiol. Open 2020, 7, 100298. [CrossRef]

46. Kono, M.; Fujita, Y.; Takeda, K.; Miyashita, K.; Tsutsumi, A.; Kobayashi, T.; Miki, Y.; Hashimoto, D.; Enomoto, N.; Nakamura, Y.; et al. Clinical significance of lower-lobe interstitial lung disease on high-resolution computed tomography in patients with idiopathic pleuroparenchymal fibroelastosis. Respir. Med. 2019, 154, 122-126. [CrossRef]

47. Kato, M.; Sasaki, S.; Kurokawa, K.; Nakamura, T.; Yamada, T.; Sasano, H.; Arano, N.; Komura, M.; Ihara, H.; Nagashima, O.; et al. Usual Interstitial Pneumonia Pattern in the Lower Lung Lobes as a Prognostic Factor in Idiopathic Pleuroparenchymal Fibroelastosis. Respiration 2019, 97, 319-328. [CrossRef] [PubMed]

48. Jacob, J.; Odink, A.; Brun, A.L.; Macaluso, C.; de Lauretis, A.; Kokosi, M.; Devaraj, A.; Desai, S.; Renzoni, E.; Wells, A.U. Functional associations of pleuroparenchymal fibroelastosis and emphysema with hypersensitivity pneumonitis. Respir. Med. 2018, 138, 95-101. [CrossRef]

49. Chen, F.; Matsubara, K.; Miyagawa-Hayashino, A.; Tada, K.; Handa, T.; Yamada, T.; Sato, M.; Aoyama, A.; Date, H. Lung transplantation for pleuroparenchymal fibroelastosis after chemotherapy. Ann. Thorac. Surg. 2014, 98, e115-e117. [CrossRef]

50. Hata, A.; Nakajima, T.; Yoshida, S.; Kinoshita, T.; Terada, J.; Tatsumi, K.; Matsumiya, G.; Date, H.; Yoshino, I. Living Donor Lung Transplantation for Pleuroparenchymal Fibroelastosis. Ann. Thorac. Surg. 2016, 101, 1970-1972. [CrossRef] [PubMed]

51. Rasciti, E.; Cancellieri, A.; Romagnoli, M.; Dell'Amore, A.; Zompatori, M. Suspected pleuroparenchymal fibroelastosis relapse after lung transplantation: A case report and literature review. BJR Case Rep. 2019, 5, 20190040. [CrossRef] [PubMed]

52. Shimada, A.; Terada, J.; Tsushima, K.; Tateishi, Y.; Abe, R.; Oda, S.; Kobayashi, M.; Yamane, M.; Oto, T.; Tatsumi, K. Veno-venous extracorporeal membrane oxygenation bridged living-donor lung transplantation for rapid progressive respiratory failure with pleuroparenchymal fibroelastosis after allogeneic hematopoietic stem cell transplantation. Respir. Investig. 2018, 56, $258-262$. [CrossRef] [PubMed]

53. Righi, I.; Morlacchi, L.; Rossetti, V.; Mendogni, P.; Palleschi, A.; Tosi, D.; Pieropan, S.; Gobbo, A.D.; Nosotti, M. Lung Transplantation as Successful Treatment of End-stage Idiopathic Pleuroparenchymal Fibroelastosis: A Case Report. Transplant. Proc. 2019, 51, 235-238. [CrossRef] [PubMed]

54. Shiiya, H.; Sato, M.; Shinozaki-Ushiku, A.; Konoeda, C.; Kitano, K.; Nakajima, J. Exacerbation of Secondary Pulmonary Hypertension by Flat Chest after Lung Transplantation. Ann. Thorac. Cardiovasc. Surg. 2020, 1-4. [CrossRef]

55. Ali, M.S.; Ramalingam, V.S.; Haasler, G.; Presberg, K. Pleuroparenchymal fibroelastosis (PPFE) treated with lung transplantation and review of the literature. BMJ Case Rep. 2019, 12, e229402. [CrossRef]

56. Aljefri, N.A.; Abothenain, F.F.; Hussein, A.M.; Saleh, W.; Alkattan, K.; Mohammed, S.F.; Alhajji, M. Idiopathic pleuroparenchymal fibroelastosis: The first case to be managed with a successful lung transplant at King Faisal Specialist Hospital and Research Center, Riyadh. Ann. Thorac. Med. 2019, 14, 94-98. [CrossRef]

57. Sekine, A.; Seo, K.; Matsukura, S.; Sato, M.; Shinozaki-Ushiku, A.; Ogura, T.; Kitami, A.; Kadokura, M.; Dohi, S.; Ichizuka, K.; et al. A case report of idiopathic pleuroparenchymal fibroelastosis with severe respiratory failure in pregnancy. BMC Pulm. Med. 2020, 20, 264. [CrossRef]

58. Portillo, K.; Guasch, I.; Becker, C.; Andreo, F.; Fernández-Figueras, M.T.; Ramirez Ruz, J.; Martinez-Barenys, C.; García-Reina, S.; Lopez de Castro, P.; Sansano, I.; et al. Pleuroparenchymal Fibroelastosis: A New Entity within the Spectrum of Rare Idiopathic Interstitial Pneumonias. Case Rep. Pulmonol. 2015, 2015, 810515. [CrossRef] [PubMed]

59. Huang, H.; Feng, R.; Li, S.; Wu, B.; Xu, K.; Xu, Z.; Chen, J. A CARE-compliant case report: Lung transplantation for a Chinese young man with idiopathic pleuroparenchymal fibroelastosis. Medicine 2017, 96, e6900. [CrossRef] [PubMed]

60. Tsubosaka, A.; Matsushima, J.; Ota, M.; Suzuki, M.; Yonemori, Y.; Ota, S.; Yoshino, I.; Tsushima, K.; Tatsumi, K.; Nakatani, Y. Whole-lung pathology of pleuroparenchymal fibroelastosis (PPFE) in an explanted lung: Significance of elastic fiber-rich, non-specific interstitial pneumonia-like change in chemotherapy-related PPFE. Pathol. Int. 2019, 69, 547-555. [CrossRef] 